\title{
Somos livres... mais ou menos - Sobre o desenvolvimento sistemático dos graus de liberdade*
}

\author{
We are Free... More or Less - On the Systematic \\ Development of Degrees of Freedom
}

${ }^{* *}$ Dirk Stederoth

Resumo: Referindo-se a perpétua estereotipia da história da filosofia, relativa à questão da liberdade do ser humano, respondida com um simples "sim" ou "não", visa o presente texto apresentar uma abordagem que permite responder a pergunta com "mais ou menos". Para esse propósito, o conceito de "graus de liberdade" colocado em foco nesta abordagem se desdobra em três dimensões distintas, da qual a primeira é baseada em diferentes níveis cognitivos. A segunda dimensão diferencia quatro fases de ação - e, portanto, fases de liberdade - e, finalmente, em terceiro lugar, são realizados um dimensionamento e graduação em relação a diferenciados níveis de desenvolvimento psicológico. $\mathrm{Na}$ última parte, o valor heurístico desses dimensionamentos individuais em relação ao problema da responsabilidade escalonada é ilustrado através de um exemplo.

Palavras-chave: Liberdade. Graus de liberdade. Responsabilidade. Responsabilidade escalanada.

Abstract: Referring to the perpetual stereotype of the history of
philosophy on the question of human freedom, answered with a simple
"yes" or "no", this text aims to present an approach that allows to
answer the question with "more or less". For this purpose, the concept
of "degrees of freedom" focused on this approach unfolds in three
different dimensions of which the first is based on different cognitive
levels. The second dimension distinguishes four phases of action -
and therefore phases of freedom - and, finally, in the third place, is
accomplished a dimensioning and graduation relative to the different
levels of psychological development. In the last section, the heuristic
value of these individual dimensioning in relation to the problem of
staggering liability is illustrated through an example.

Keywords: Freedom. Degrees of freedom. Responsibility. Staggering liability.

* O presente texto foi apresentado em 20 de março de 2013, por ocasião de uma palestra pública no Programa de Pós-Graduação em Filosofia da PUCRS.

* * Doutorado em Filosofia (2000) e Livre-Docência em Filosofia (2013) pela Universidade de Kassel. Professor de Filosofia no Instituto de Filosofia da Universidade de Kassel.

\begin{tabular}{|l|l|l|l|l|l|}
\hline Veritas & Porto Alegre & v. 58 & n. 3 & set./dez. 2013 & p. 528-544 \\
\hline
\end{tabular}


Examinando os diversos períodos da História da Filosofia em que o problema da liberdade da vontade dos seres humanos foi filosoficamente tratado, encontramos uma persistente estereotipia: até os dias de hoje, para a questão se o ser humano é livre ou não, surge igualmente, de forma reflexiva, um horizonte de resposta dual: sim ou não. Resumidamente: ou existe liberdade ou não existe - "tertium non datur". Outras formas de resposta, como "mais ou menos", "tanto livre como também não livre", parecem de início excluídas. Exatamente essas tomei como ponto de partida, uma "posição-mais-ou-menos" para, através desse caminho, examinar o relegado conceito dos graus de liberdade e preenchê-lo com conteúdo. Desejo indicar o resultado obtido, mencionando antes que, em um primeiro passo, apenas darei uma visão superficial da abordagem global e, em um segundo passo, demonstrarei de forma resumida o valor heurístico do enfoque no problema específico do conceito de responsabilidade.

\section{As dimensões}

O enfoque global parte, de maneira singela, de três dimensões nas quais o problema da liberdade prática se diferencia. Desejo lhes apresentar essas dimensões com referência aos correspondentes desideratos nos debates dos últimos anos em relação ao livre arbítrio.

A primeira (e talvez mais importante) dimensão responde à quase completamente negligenciada diferenciação de capacidades psíquicas ou níveis, nesses debates. Na regra, as contribuições se provam como representações conscientes ou inconscientes de um sistema dual, na qual, de um lado, está uma definida esfera causal de processos psicológicos ou neuropsicológicos e, do outro lado, uma esfera de ações motivacionais conscientes. Em torno desse sistema dual, se agrupam então - se essa visão grosseira é permitida -, as três principais posições do debate. Os "Indeterministas" (geralmente representados pelos filósofos com orientação clássica), que assumem que apenas a esfera dos processos fisiológicos pode ser vista como determinada estritamente de forma causal, enquanto, na esfera dos motivos - de forma exagerada - um reino da liberdade pode ser constatado; os "deterministas", em contraposição (representados por neurocientistas cognitivos e psicólogos empíricos), reconhecem os dois lados do sistema dual como relevante para a psicologia do dia-a-dia, mas, consideram, no entanto, que a suposição de que a liberdade seja possível no nível dos motivos seja apenas uma construção social ou uma ilusão, uma vez que cientificamente ou em psicologia experimental teria se mostrado que não existem decisões 
livres. A terceira corrente, representada pelos "compatibilistas", parte do princípio de que liberdade e necessidade são compatíveis entre si e que os dois lados do sistema dual apenas são as duas faces de uma mesma moeda. Está claro que, nessa representação, as diversas posições tiveram que ser simplificadas e que com essa caracterização básica foi feita justiça com um ou outro autor. Mas, trata-se menos de uma inconfessa intenção da minha parte do que a necessária brevidade da representação.

Em relação a esse sistema dual desejo sugerir uma diferenciação vertical escalonada que classifica o comportamento humano em seis formas de comportamento que mostram graus individuais de liberdade. Visando explicar melhor essa diferenciação, permitam-me inicialmente apresentar duas premissas terminológicas. Talvez lhes cause surpresa que eu, nesse contexto, fale de "formas escalonadas de comportamento", já que o conceito de "comportamento" é aparentado ao campo da biologia e do correspondente determinismo. Por essa razão quero aqui deixar claro (e essa é a primeira premissa terminológica), que todo o "Ser-NoMundo" prático do homem representa um comportamento em relação ao seu ambiente natural e social. Nessa sua prática o homem sempre está em relação ao seu meio ambiente, lida com ele, interage com ele. Por essa razão, parece-me que o conceito "comportamento" melhor se aplica a essa relação. No entanto, há ainda necessidade de melhor diferenciar esse conceito: por um lado numa atuação provocada por fatos, portanto causal (poderíamos aqui falar de "interação", ou melhor - a semelhança do uso na biologia - de "comportamento no sentido mais estrito"), e, por outro lado, de um comportamento provocado por motivos, geralmente caracterizado por "ação".

Além disso, devem os senhores ter se admirado de que falei de "graus de liberdade". Isso é explicado por uma segunda premissa terminológica que, embora apoiada sobre a corrente identificação de liberdade e autodeterminação, é ampliada na medida em que o grau de liberdade de um comportamento é medido pelo grau de participação do eu na decisão do seu comportamento. Quanto maior a participação desses fatores na decisão de comportamento não determinados pelo eu, menor é o grau de autodeterminação e consequentemente de liberdade. Ou, formulado de forma inversa: quanto mais fatores o eu decide no seu comportamento, tanto maior é o grau de autodeterminação e a liberdade. Precisamente essa segunda premissa básica é também a pedra fundamental do conceito global e se constitui no fulcro a ser introduzido no debate sobre liberdade.

Mas, como se apresentam individualmente as diferentes formas de comportamento sugeridas no conceito anterior? (Figura 1). 
6.) Motivação lógico-racional

5.) Motivação normativa

4.) Motivação subjetiva

3.) Modelos de comportamento espontâneo

2.) Modelos de comportamento adquirido

1.) Modelos de comportamento inato

Motivos: comportamento consciente

Causas: comportamento não-consciente

Grau de Liberdade

Figura 1

Observando o gráfico, perceberemos, sem dificuldades, a referida sistemática dual mencionada e certamente queimará na mente a pergunta do que esse conceito se diferencia do recém-criticado. A diferença se torna clara apenas quando a relação entre os diferentes níveis é observada mais precisamente, razão pela qual cabe fazer um apelo à paciência. Principiando pelos três níveis inferiores, o primeiro nível (Figura 1) se refere à liberdade em um nível de fronteira, na medida em que se trata de formas de comportamento inatas, próximas a regras homeostáticas e, de forma mais ampla, comportamento coordenado por herança (infelizmente não posso entrar aqui na diferenciação interna detalhada que pode ser vista na figura). O comportamento decorrente desse modelo de comportamento inato é, no mais alto grau, não autodeterminado, uma vez que é determinado por um programa genético. Resumindo: embora a epigenética tenha revelado descobertas quanto à herança de características (quase em sentido lamarckiano) em alguns campos, essa variabilidade, se pudesse ser estendida a outras áreas, é apenas possível através da transmissão de gerações, e não ao nível do indivíduo. Isso é definido no nível de modelos inatos de comportamento pela prévia informação genética.

O segundo nível (Figura 1), já apresenta outra aparência, já que aqui se trata de modelos de comportamento adquiridos, cujo desenvolvimento é atribuído à experiência do indivíduo. Os processos relevantes são a facilitação, condicionamento e aprendizagem procedural. Todos esses processos estão ligados ao horizonte de aprendizagem do indivíduo e são, portanto, produzidos em maior grau pelo comportamento do eu do que 
os modelos de comportamento inatos. No entanto, o treinamento desse modelo de comportamento exige repetição e é, portanto, ligado à repetida existência de condições externas semelhantes. Aqui, o eu autocontrolado - através da dependência da experiência para o comportamento já alcançou certo grau de autodeterminação, mas é completamente dependente das condições dadas de situação para desenvolver esses modelos de comportamento e adquirir autonomia parcial.

Isso é diferente no terceiro nível, do comportamento espontâneo (Figura 1), que se refere a fenômenos como "proteísmo"1, jogos e criatividade. Nesses fenômenos, alterações de comportamento não são estritamente vinculadas a eventos dados, sendo desenvolvidas de forma espontânea, razão pela qual se pode falar de um grau mais elevado de autodeterminação. No entanto, não se deve pensar em uma "creatio ex nihilo", já que essa formação de comportamento se constrói obviamente sobre modelos existentes, colocando-os em um novo contexto situacional ou respondendo a novas exigências de situação, através de uma inovada contextualização de modelos dados, de forma que se trata, antes, de uma "visão" inovadora ou incomum do já dado.

Os três níveis esquematizados estão subordinados a ocorrências causais e, em regra, acontecem no ser humano de forma não consciente, o que não deve significar que, em principio, estejam ausentes da consciência. A sugestão de não consciência significa, antes, que motivos para agir nesses níveis podem não ter efeito imediato, na medida em que os modelos de comportamento gerados nesse nível comportamental se apresentam como máximas de ação à consciência.

Dessa forma, já é tema de análise o próximo nível, cabendo lembrar que nesse âmbito a esfera da ação, portanto um comportamento com base em motivos foi alcançado (Figura 1). Esse aparente salto em um domínio completamente diferente concebe-se dentro do conceito apresentado, porém mais fluido do que a primeira vista sugere, razão pela qual cabe permanecer um pouco nessa passagem.

Motivos se diferenciam de causas em pelo menos um aspecto muito importante: causas são ligadas de forma imediata a seus efeitos, enquanto motivos tornam-se válidos apenas após um processo de deliberação. A especificação de um motivo para ação implica a escolha entre diversas opções de ação e a seleção de uma opção específica possui um motivo. Certamente existem motivos para a escolha de outra opção, mas está na

1 N. de E.: no original alemão, "Proteismus". Uma tradução aproximada seria "mutabilidade de opinião", "concepção" ou "comportamento". "Proteu", deus marinho na mitologia grega, filho de Poseidon e Tétis, é, como é bem sabido, figura emblemática da metamorfose e constante mudança de forma ou aparência. 
natureza de cada processo de seleção o diferencial dos diversos motivos de decisão e a validação de um desses motivos.

As mais conhecidas e divulgadas formas desses processos de decisão são as considerações apenas subjetivas de motivos para ação (Figura 1). Exemplos: "esta opção combina mais comigo", "sempre agi assim", "essa opção me ocorreu agora e me parece espontaneamente a melhor". Examinando esses processos de decisão subjetivos mais de perto (como o fez Dietrich Dörner), verifica-se que podem ser rastreados a níveis não conscientes inferiores. Um motivo subjetivo como "sempre fiz assim" não é nada mais do que a transmissão na esfera dos motivos do nível "modelos de comportamento adquirido", e o motivo subjetivo "essa opção me ocorreu agora e me parece espontaneamente a melhor" pode ser rastreada ao nível de "modelos de comportamento espontâneo". O nível de motivação subjetiva mostra-se ainda preso a modelos de comportamento causais, mas se diferencia desses níveis porque esse modelo de comportamento causal é produzido por um processo de decisão consciente. Mesmo que esse processo de decisão subjetivo - seguindo Dörner - esteja assentado sobre um não consciente alinhamento entre forças de motivos das diferentes opções, é alcançado um novo nível de liberdade através do estabelecimento consciente de relações entre essas opções.

Isso se torna especialmente claro ao se considerar que motivos não são apenas de natureza subjetiva. Quando examinamos o próximo nível, correspondente à motivação normativa (Figura 1), os motivos desse nível se orientam segundo regras dadas que - dito de forma geral - criam um grupo para a sua conexão. Referimo-nos aos princípios que regram a filiação a um grupo, sendo nesse momento indiferente de qual grupo se trata, grupo de pares, comunidade religiosa, partido político ou estabelecimento estatal.

O processo de decisão de uma pessoa no nível da motivação normativa parece então - já que tem que se orientar por regras dadas - sensivelmente menos livre do que aquele do nível da motivação subjetiva, uma vez que o indivíduo participa muito pouco (caso participe), no estabelecimento dessas regras, razão pela qual o motivo de ação lhe parece imposto. No entanto, as aparências enganam, na medida em que a pessoa pode se decidir a contrariar essas regras. Uma decisão de quebra de regras não mais pertence ao nível de motivação subjetiva, mas é normativa, embora normativo-negativa - podemos dizer uma consciente quebra de regras. Por essa razão, ela deve ser considerada mais livre em relação ao nível da motivação subjetiva.

Esse grupo específico de regras pode entrar em conflito entre si, como por exemplo, a filiação à minha comunidade religiosa, que me ordena 
à negação de prestação do serviço militar, que não me concede as leis do meu país, ou a filiação ao meu grupo de pares, que permite o uso de brincos permanentemente, enquanto o estatuto da minha associação esportiva de futebol o proíbe. Esses "dilemas normativos" - como os poderíamos chamar - são geralmente solucionados de duas maneiras. $\mathrm{O}$ caminho subjetivo é o de que os indivíduos tentam atingir uma coerência normativa, fazendo parte de grupos compatíveis, de forma que o conflito entre as regras de comunidades religiosas pietistas e os estatutos de clubes de "swing" não ocorram. O caminho objetivo é o de que algumas regras assumem o estatuto de meta-regras e assim adquirem uma hierarquia superior. Em geral, essa tarefa é preenchida pelas constituições de estado, mas também pode ser atribuída a princípios religiosos.

$\mathrm{Na}$ necessidade do mecanismo de meta-regras se manifesta o germe da motivação que caracteriza o próximo nível (Figura 1). Na motivação lógico-racional, trata-se de motivos que, pela sua origem lógica e sensata, podem exigir uma validade universal que não se restringe a um grupo, mas deve valer para todos igualmente, já que estão comprometidos com um discurso racional. O "padrinho" desse nível é naturalmente o imperativo categórico kantiano, que não apenas visa máximas de ação válidas, mas é para Kant a única - para a presente abordagem a mais elevada - forma de liberdade prática. Esse nível deve ser considerado mais livre em relação ao normativo, já que aqui o sujeito que decide, por um lado, retira de si mesmo os motivos de ação gerados pela sua razão, e apesar disso, por outro lado, pode estar seguro de sua validade universal. Por mais paradoxal que pareça: no mais alto sentido, livre é exatamente o homem onde não há mais alternativas para ele, caso nos apartemos da infundada construção de um "mal radical". Ao tratar com plena consciencia motivos de ação razoáveis em relação a si mesmos, como mentir para proteger um amigo - como diz o velho dilema -, então abandona-se o nível da motivação lógico-racional e processa-se um motivo de ação razoável (não mentir) como normativo, em contradição a outra motivação normativa (a amizade significa ajudar-se mutuamente). A avaliação do bem pertence, portanto, ao discurso normativo, já que o discurso lógico-racional somente pode conhecer o bem universal que não exige nenhuma avaliação. Nesse ponto, cessa a aproximação anterior ao pensamento kantiano radical, em relação a toda diluição de hierarquias de valores, etc. No entanto, não cabe aqui aprofundar o assunto, mas avançar para a segunda dimensão.

A segunda dimensão (Figura 2) adota inicialmente o fato de que, na história da filosofia, tratou-se e trata-se de duas formas distintas de liberdade prática (Figura 2). De forma clássica, diferencia-se a liberdade volitiva da liberdade de ação, sendo ambas as formas de liberdade 
independentes nessa altura. Diz David Hume (um representante da liberdade de ação) que a liberdade volitiva é determinada. Contudo, existe liberdade quando a ação que se segue à vontade não encontra obstáculos. Posso de fato dizer, com uma formulação modificada de Schopenhauer, "não querer o que quero, mas fazer o que quero", na medida em que as circunstâncias o permitem. Em relação a essa liberdade de ação, a liberdade volitiva é conceitualmente concebida de forma diferente. Aqui, trata-se apenas se o meu querer, ou, dito de forma kantiana, a máxima do meu querer, pode ser decidida livremente. Não é necessário mencionar que ambas as matérias se preocupam com problemas diferentes, e é, portanto, altamente problemático considerar que nos debates atuais as duas formas de liberdade raramente são mantidas claramente separadas.

Com essas duas formas de liberdade são abordadas duas fases totalmente diferenciadas de ação, na medida em que a liberdade volitiva se orienta para a determinação de vontade existente no inicio de uma ação enquanto a liberdade de ação se orienta a concreta execução dessa determinação de vontade. Assim, uma ação poderia ser dividida em duas fases (Figura 2): uma primeira fase de motivação da ação, que compreende o problema da liberdade volitiva, e uma segunda fase de execução da ação ou a ação em si, para o qual o problema da liberdade de ação é pertinente.

Existe um modelo na psicologia da ação que, além dessas duas fases, adiciona duas mais, incluidas na presente abordagem. O chamado modelo-Rubikon das fases de ação, desenvolvido por Heckhausen e Gollwitzer nos anos 1980 do século 20, adota quatro diferentes fases. Esse modelo foi desenvolvido por Heckhausen e Gollwitzer para o estudo de diferentes estados mentais nas ações, (posteriormente) a presente abordagem tenta tornar esse modelo útil para a problemática da liberdade. As quatro fases, com as respectivas formas de liberdade, seriam as seguintes (Figura 2):

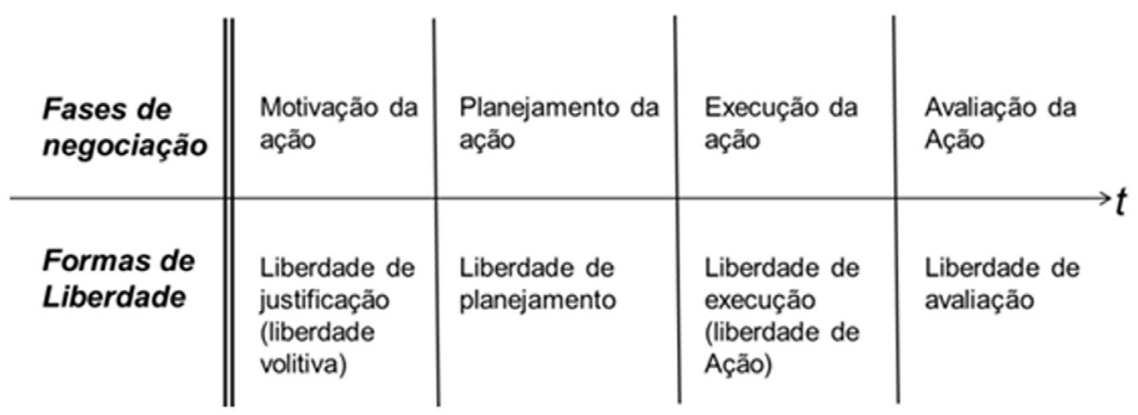

Figura 2 
Permitam-me mais alguns comentários com relação a esse modelo ou às suas fases individuais. A primeira fase da "motivação de ação" (Figura 2) parte de condições situacionais dadas, em relação às quais a ação procura reagir ou influenciar. Nessa fase, o processo de decisão, através do qual diversas opções são ponderadas e decididas, está ausente (Figura 2). Tomada uma decisão, é importante a opção selecionada ser planejada e relacionada às condições de situação concretas, o que distingue o planejamento de ação. No entanto, deve ser dito que entre essas duas primeiras fases frequentemente ocorrem laços, uma vez que o planejamento concreto poderá exibir uma inadequação da opção selecionada em relação às condições dadas, o que pode conduzir a uma atualização do processo de decisão (Figura 3). Nesse laço fica demonstrado que o grau de liberdade na motivação da ação é mais alto do que no planejamento da ação, na medida em que o último está vinculado de forma muito mais completa às condições externas dadas.

Essa vinculação se mostra ainda mais forte na terceira fase - execução da ação (Figura 2) -, embora possa se dizer que sou livre quando a execução da ação me é concedida, isto é, quando a liberdade não é decidida por mim, mas dependente das condições externas. Assim, pode suceder que se caia em um laço também nessa fase (Figura 3), quando as condições de situação na execução de outra opção de ação ou a modificação dos parâmetros de ação o exigirem. Demonstra-se, assim, nesse ponto, que a representação esquemática da dinâmica dessa dimensão somente pode ser justificada de forma limitada.

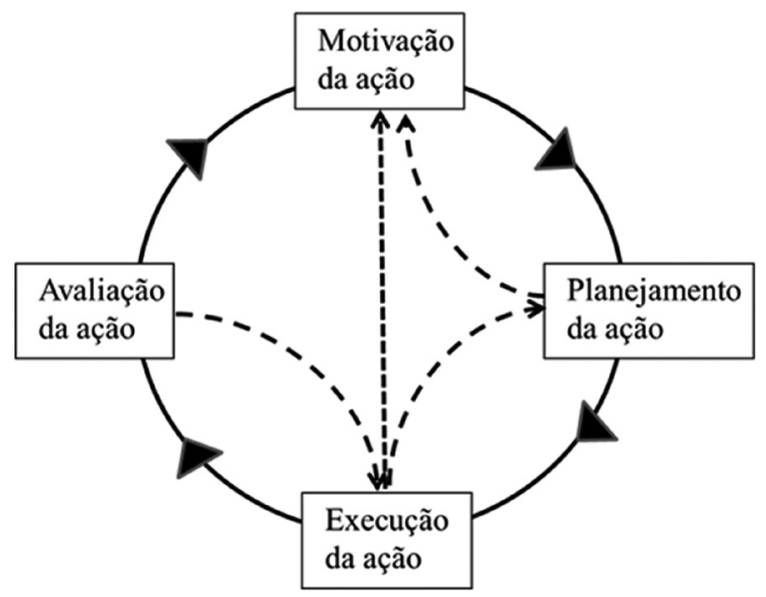

Figura 3 
Isso também se reflete na última fase de ação (Figura 2), referente à posterior avaliação da ação executada, que naturalmente entra ou pode entrar em uma nova motivação de ação (Figura 3), de forma que o fim se fecha no início. Além disso, são identificados processos reflexivos durante a execução da ação que, por sua vez, influenciam os mesmos.

Para finalizar, pode ser afirmado - como já mencionado - que, para essa dimensão, o grau de liberdade diminui continuamente da primeira à terceira fase (Figura 4), já que a dependência de condições externas também cresce continuamente. $\mathrm{Na}$ quarta fase, no entanto, o grau se eleva novamente, já que a posterior avaliação da ação concluída novamente compete ao sujeito da ação, embora também aqui a influência de avaliações verbais ou não verbais de outras pessoas não deva ser subestimada.

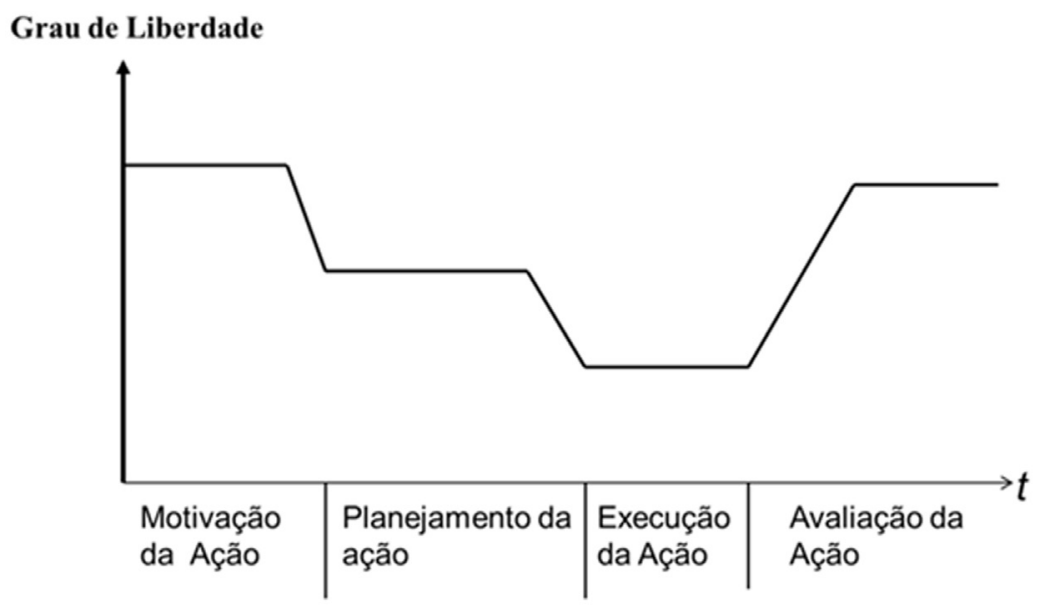

Figura 4

A terceira dimensão, genética (Figura 5), considerado de forma precisa, divide-se em dois diferentes domínios, pois de um lado está a liberdade do ser humano em uma dimensão da história da humanidade e, de outro, a construção do processo de liberdade que cada ser humano, em seu desenvolvimento individual, tem que realizar. Eu me concentrarei na última parte, embora a primeira não seja menos importante e aqui se poderia aprofundar seguindo o dito de Hegel sobre a história como "progresso na consciência da liberdade", embora entrando dessa forma em um campo realmente muito amplo. 


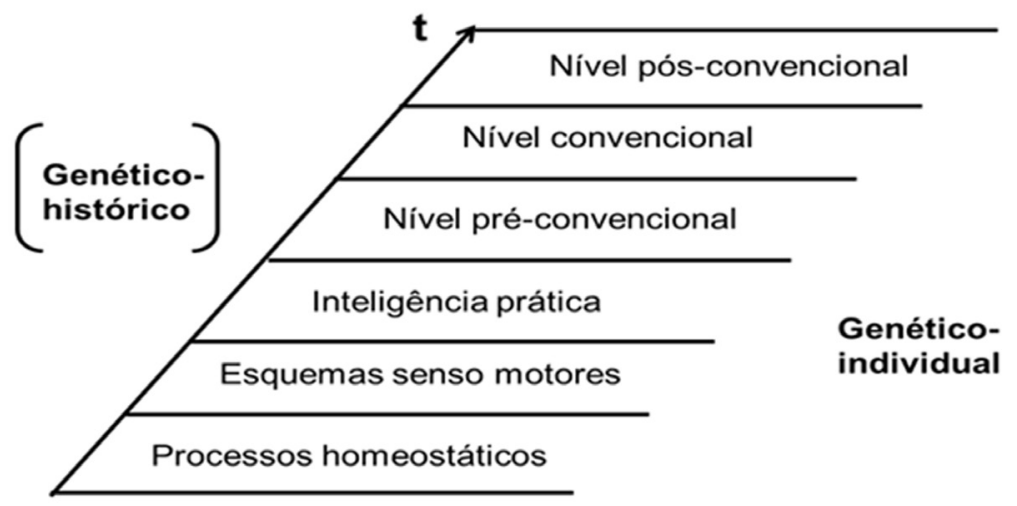

Figura 5

No que diz respeito ao desenvolvimento da liberdade individual, inspirei-me na diferenciação sistemática dos níveis de desenvolvimento das abordagens de Piaget e Kohlberg e, em última instância, fiz um cruzamento dos dois. Acima de tudo, isso foi necessário porque os famosos estudos de Kohlberg para o desenvolvimento da moral apenas começam com uma idade que aqui foi designada como "pré-convencional", já que ele buscava a avaliação de relatos verbais para dilemas morais que evidentemente não poderiam ser produzidos por bebês e crianças pequenas. Os estudos sobre desenvolvimento cognitivo de Piaget, no entanto, recuam até a idade de bebês e podem ser ampliados em face de novos estudos nesse campo (como os de Daniel Stern e outros). A relação dessas duas abordagens com o conceito da autodeterminação e inclusive com a problemática da liberdade surge a partir do conceito de Piaget da "equilibração", com consequente desenvolvimento cognitivo através de um processo contínuo de discussão entre o eu e o ambiente, em que se alinha um estado de equilíbrio. Em que grau essa abordagem é análoga ao conceito de autodeterminação do presente enfoque não pode ser analisado em detalhes neste momento.

Pequenos indícios encontram-se, no entanto, na extensa correspondência do nível do desenvolvimento individual com os degraus verticais acima desdobrados. O primeiro nível (Figura 5), que Piaget liga a processos homeostáticos, é análogo aos modelos de comportamento inatos, quando se trata de desdobramentos de comportamentos inatos que buscam compensação de perturbações em relação às condições ambientais. A segunda fase (Figura 5), dos "esquemas senso-motores", 
é semelhante ao degrau "modelos de comportamento adquirido" em relação a processos habituais, a partir dos quais se desenvolvem "sentidos autocentrados",, como é formulado pela recente pesquisa infantil. No terceiro degrau (Figura 5), da "inteligência prática", essa é análoga ao degrau "modelos de comportamento espontâneo", em questão de jogos de ligações e experimentação de esquemas adquiridos em novas situações de ambiente.

No que diz respeito aos demais níveis de desenvolvimento inspirados em Kolhberg, esses são comparáveis com os três degraus verticais dos motivos de ação. A fase pré-convencional (Figura 5) se distingue por uma "perspectiva individual concreta" (que corresponde à acima mencionada "motivação subjetiva"), a convencional (Figura 5) pela "perspectiva de um membro de uma sociedade" (que corresponde largamente à "motivação normativa"), e a pós-convencional (Figura 5) por uma "perspectiva ordenada pela sociedade" (que principalmente pode ser associada, em sua orientação de princípios, com a "motivação lógico-racional"). Isso deve bastar na esquematização da terceira dimensão, a dimensão genética.

Reunindo agora as três dimensões (Figura 6), forma-se um espaço sistemático de diferenciação da liberdade prática, em que, pela localização no espaço, diferentes campos sobrepostos ocorrem, nos quais o problema da liberdade especificamente se projeta.

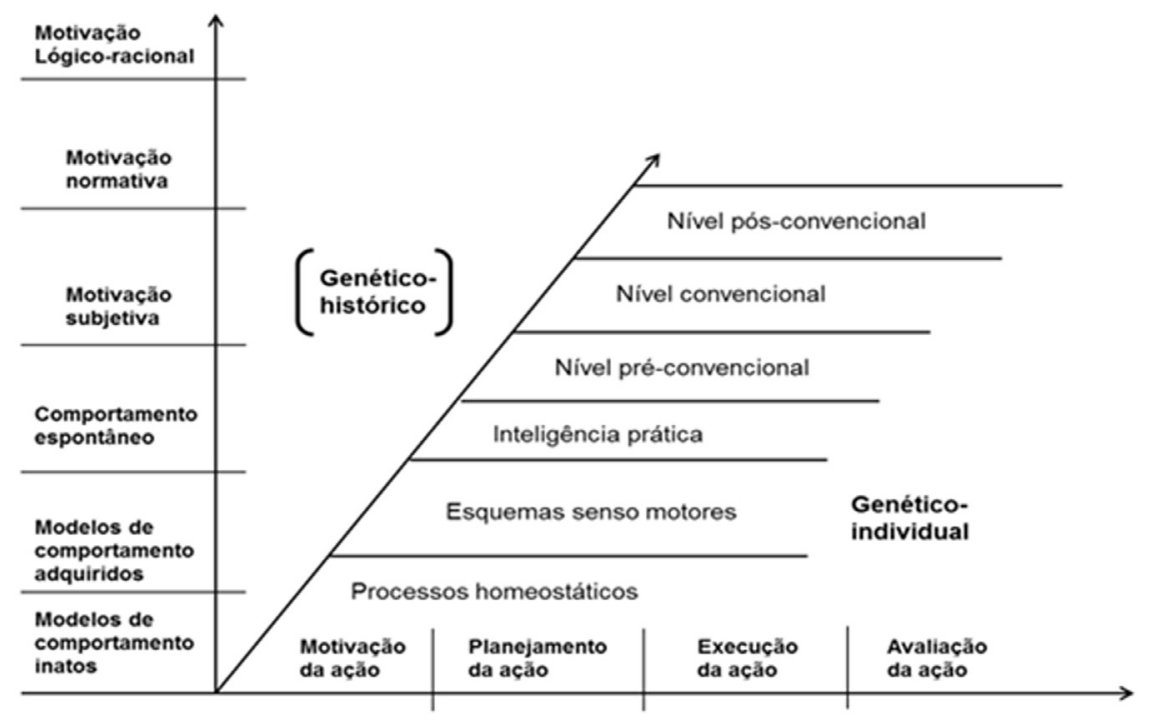

Figura 6 
No entanto, nesse espaço nem todos os campos estão preenchidos, na medida em que, por exemplo, os "processos homeostáticos" da dimensão genética apenas se sobrepõem aos "modelos de comportamento inatos" da dimensão vertical, e não com os demais níveis verticais. Excluindo todos os campos que não podem se sobrepor logicamente, obtemos uma representação em forma de escada do espaço de diferenciação (Figura 7).

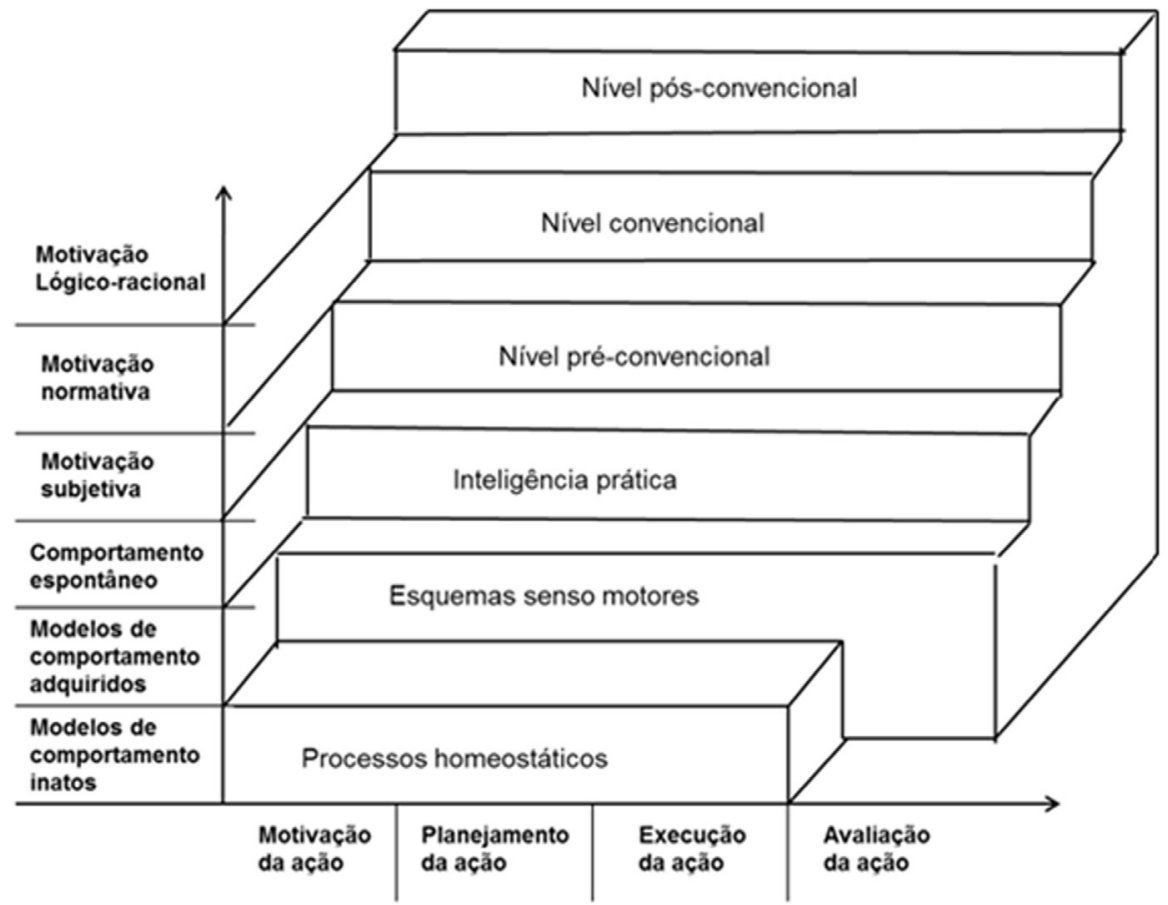

Figura 7

Com esse gráfico, está encerrada a primeira parte da minha apresentação, em que tratei simplesmente de fornecer uma visão ampla sobre o conceito. Gostaria, na segunda parte, de comentar de forma rápida o problema da relação entre liberdade e responsabilidade, na medida em que essa exposição revela novas perspectivas sobre problemas correntes. No presente contexto, buscarei discutir a questão da responsabilidade, escalonada nas três dimensões mencionadas. 


\section{Liberdade escalonada - Responsabilidade escalonada?}

Principiando com as dimensões verticais (Figura 1), gostaria de inicialmente assinalar que existem inter-relações dinâmicas entre os degraus individuais, das quais uma é esboçada em mais detalhe. Supondo que uma pessoa adere a certo grupo, por exemplo, um agrupamento de extrema direita, então o grupo impõe certas condições normativas ao indivíduo, sendo que essa pessoa somente poderá manter filiação ao grupo se alinhar as suas ações aos requisitos normativos. Essas exigências normativas podem, em alguns casos, coincidir com as atitudes habituais e próprias desse indivíduo; no entanto, em alguns casos não, e essa pessoa possivelmente terá que se decidir contra a sua estrutura motivacional subjetiva, por motivos normativos do grupo, infligindo-se certa violência pessoal. Quanto mais frequentemente essa pessoa realiza essas ações normativamente fundamentadas, tanto mais se formam nela estereótipos de ação que produzem esse tipo de comportamento. Isso não significa nada mais que o fato de que um motivo consciente normativo inicial de ação baixa ao nível do modelo de comportamento adquirido (Figura 8).

6.) Motivação lógico-racional

5.) Motivação normativa

4.) Motivação subjetiva

3.) Modelos de comportamento espontâneo

2.) Modelos de comportamento adquirido

1.) Modelos de comportamento inato

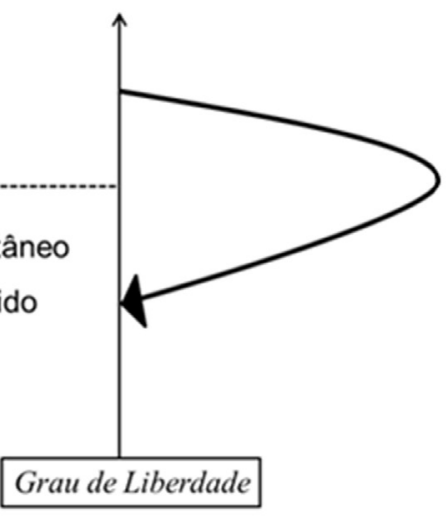

Figura 8

Uma vez estabelecido tal estereótipo de modelo de comportamento, ocorre uma segunda dinâmica uma vez que esse modelo surge no nível da motivação subjetiva como comportamento comprovado, ou, de forma mais geral, como uma obviedade subjetiva (Figura 9). 
6.) Motivação lógico-racional

5.) Motivação normativa

4.) Motivação subjetiva

3.) Modelos de comportamento espontâneo

2.) Modelos de comportamento adquirido

1.) Modelos de comportamento inato

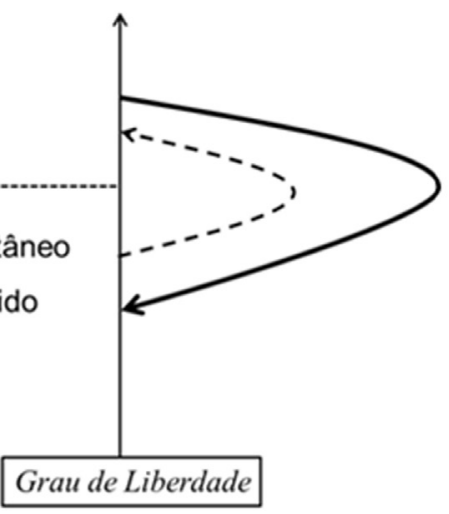

Figura 9

Essa dinâmica torna-se interessante no contexto da questão da relação entre liberdade e responsabilidade, pois a justificação para uma ação normativa, na qual o comportamento no exemplo esboçado teve origem, tem um grau de liberdade relativamente elevado. Se deixássemos o grau de liberdade ocorrer de forma proporcional ao grau de responsabilidade, como indica a prática de nossa jurisprudência, então após a formação de um estereótipo de comportamento não apenas o grau de liberdade, mas também o da responsabilidade cairia. Isso teria consequências fatais, pois uma pessoa que por repetição de um estereótipo desenvolvesse comportamento agressivo teria menor responsabilidade e, correspondentemente (no contexto jurídico), menos culpa atribuída.

Essas consequências somente poderiam ser evitadas se uma "dissociação dinâmica entre liberdade e responsabilidade" fosse produzida, tal que a responsabilidade pela decisão de aderir a um grupo violento não se extinguisse com a formação de estereótipos. Além disso, uma parte da decisão permanece no nível normativo, na medida em que uma pessoa pode, a qualquer tempo, decidir-se novamente a deixar o grupo, embora isso se torne gradualmente mais difícil em função de costume crescente.

Agora, para prosseguir com as fases de negociação (Figura 10) e a problemática da responsabilidade, não quero desprezar os aficcionados de histórias policiais. Consideremos, pois, um assassinato clássico. O que nos diz a previamente descrita diferenciação das fases de negociação sobre as fases de um crime de homicídio? Primeiramente, podemos distinguir três fases até a ação. A primeira fase da motivação da ação 
é pouco afetada por influências externas, tem, portanto, em relação às fases seguintes, o mais alto grau de liberdade. Além disso, os mencionados psicólogos Heckhausen e Gollwitzer já haviam constatado que a consciência nessa fase é muito orientada à realidade e aberta para diferenciadas impressões. No entanto, na segunda fase, do planejamento da ação, modifica-se esse estado de consciência para uma orientação focada, na qual a percepção é voltada seletivamente ao alvo, o que também é válido para a terceira fase. Além disso, a fase do planejamento de ação depende muito mais das condições de situação, com o qual o alvo de ação decidido deve ser comparado. Isso se torna ainda mais forte na execução concreta da ação. Como já mencionado acima, reduz-se de fase a fase o grau de liberdade e, com isso, o grau de responsabilidade (Figura 10).

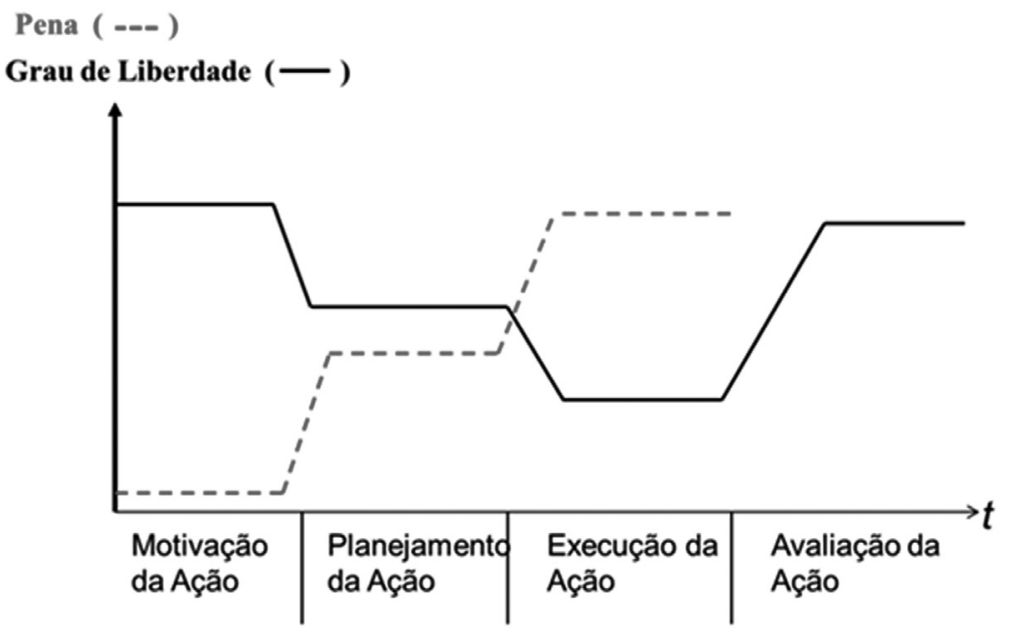

Figura 10

Agora o apreciador de contos criminais fica surpreso, pois sabe que, com o andamento da ação, portanto da intenção, preparação até a execução, a pena e a culpa crescem (Figura 10). Quem pretende um assassinato não é punido, quem o planeja já o é, mas a mais alta pena é atribuída à execução, sendo igualmente mais alta a culpa quando o autor apresenta o menor grau de liberdade e responsabilidade. Poderíamos chamar o caso de "dissociação gradativa da responsabilidade e da culpa". A inversa "dissociação gradativa da responsabilidade e do mérito" vale 
igualmente pelos mesmos motivos, razão pela qual não será debatida.

Em vez disso, vamos discutir brevemente as fases de desenvolvimento individual (Figura 5), e aqui encontra-se um contraste idiossincrático entre o discurso pedagógico e o jurídico. Iniciando pelo discurso jurídico, estabelece o direito federal alemão, por xemplo, uma clara fronteira na responsabilidade por crimes: "Inimputável de culpa é quem, ao cometer o ato, não atingiu a idade de quatorze anos" (StGB, §19). De certo modo pode-se apoiar isso nas mencionadas fases de desenvolvimento, já que com quatorze anos de idade - conforme Kohlberg - o nível convencional está completamente desenvolvido (Figura 5). Somente então, quando a pessoa pode compreender a estrutura normativa de uma entidade estatal, pode ela também ser condenada pelo Estado. Por mais plausível que isso soe, tanto mais implausível se torna em um segundo ponto de vista, quando se considera que o mais tardar desde o Émile de Rousseau é lugar comum pedagógico que crianças com menos de 14 anos podem, até mesmo devem ser responsabilizadas pelos seus atos. Especialmente na tradição das reformas educacionais, o ensino da responsabilidade própria nas ações representa uma das metas principais, implementada, a modo de tentativas, através de repúblicas ou tribunais infantis.

As consequências dessa "dissociação de responsabilidade de crianças na prática pedagógica e a inimputabilidade de crianças na prática jurídica" não serão aqui aprofundadas, mas, muito mais, tomadas como oportunidade de novamente destacar que, com relação à questão da liberdade, não pode existir um claro sim ou não, senão um complexo "mais ou menos".

(Traduzido do alemão por Luiz Roberto Stern)

\section{Endereço postal:}

Universität Kassel

Institut für Philosophie

Nora-Platiel-Str. 1

D-34109 Kassel

E-mail: d.stederoth@uni-kassel.de

Data de recebimento: 10/05/2013

Data de aceite: 15/08/2013 